\section{Assessment of Patient Absorbed Radiation Dose during Hysterosalpingography: A Pilot Study in Southwest Nigeria}

\author{
Achuka J. A. ${ }^{* *}$, Aweda M. A. ${ }^{2}$, Usikalu M. R. ${ }^{1}$, Aborisade C. \\ A. ${ }^{3}$
}

\begin{abstract}
Background: Hysterosalpingography (HSG) is an indispensable tool for diagnosing infertility in females. The procedure exposes female reproductive organs to ionizing radiation as the genitals are irradiated during the process. Investigating patient absorbed dose during the procedures is essential for effective radiological protection of the patient.
\end{abstract}

Objective: This study aims to investigate the radiation dose received by patient during HSG examination in the study environment in order to enhance optimization of procedures and the associated dose, thereby minimizing radiation risks.

Material and Methods: The prospective pilot study, was conducted in four tertiary healthcare institutions in Southwest Nigeria. Thermoluminescence dosimeter (TLD 100) was used to determine the Entrance Surface Dose (ESD) of 80 patients presented for HSG investigation. The corresponding effective dose, ovary, uterus and urinary bladder doses were evaluated using PCXMC software.

Results: The mean entrance surface doses (ESD) obtained from the four centers were $18.58 \pm 6.31 \mathrm{mGy}, 15.18 \pm 2.27 \mathrm{mGy}, 17.44 \pm 3.43 \mathrm{mGy}$ and $34.24 \pm 11.98 \mathrm{mGy}$ for SW1, SW2, SW3 and SW4 centers, respectively. The corresponding mean of effective doses were $1.54 \pm 0.63 \mathrm{mSv}, 1.24 \pm 0.28 \mathrm{mSv}, 1.41 \pm 0.30 \mathrm{mSv}$ and $2.53 \pm 0.94 \mathrm{mSv}$ for SW1, SW2, SW3 and SW4 centers, respectively. The resulting mean doses to the ovary, urinary bladder and uterus were also presented.

Conclusion: The results obtained in general are comparable with international standards. It was, however, recommended that study centers with high doses should conduct dose audit in order to enhance patient safety.

Citation: Achuka JA, Aweda MA, Usikalu MR, Aborisade CA. Assessment of Patient Absorbed Radiation Dose during Hysterosalpingography: A Pilot Study in Southwest Nigeria. J Biomed Phys Eng. 2020;10(2):131-140. doi: 10.31661/jbpe.v0i0.1054.

\section{Keywords}

Hysterosalpingography; Thermoluminescence Dosimeters; Entrance Surface Dose; Effective Dose; Organ Doses; Radiation Protection; Patient Safety

\section{Introduction}

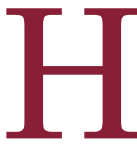
ysterosalpingography (HSG) is an X-ray diagnostic procedure for imaging of the uterus and fallopian tubes. Its applications consist of diagnosing causes of infertility in females, showing areas of scarring inside a fallopian tube or changing in the uterine cavity, evaluating patients who have had several miscarriages, investigating patients prior to myomectomy, diagnosing cervico-uterus anomalies and locating intrauterine device that cannot be seen on a pelvic examination [1-3].
${ }^{1} \mathrm{PhD}$, Department of

Physics, Covenant Uni-

versity Ota, Ogun State,

Nigeria

${ }^{2} \mathrm{PhD}$, Department

of Radiation Biology,

Radiotherapy and $\mathrm{Ra}$ -

diodiagnosis, College of

Medicine, Lagos Univer-

sity Teaching Hospital,

Idi-Araba, Lagos, Nigeria

${ }^{3} \mathrm{PhD}$, Department of

Physics and Engineer-

ing Physics, Obafemi

Awolowo University, Ile-

Ife, Osun State, Nigeria

*Corresponding author: J. A. Achuka

Department of Physics,

Covenant University Ota

Ogun State, Nigeria

E-mail: justina.achuka@

covenantuniversity.edu.

ng

Received: 29 November 2018

Accepted: 10 December 2018 
The topmost indication for HSG investigations is infertility $[4,5]$. Worldwide, $15 \%$ of reproductive-aged couples are affected by infertility. While in Sub-Sahara Africa more than $30 \%$ of women between the ages of 25 and 49 suffer from secondary infertility $[6,7]$. Secondary infertility has also been reported in Nigeria $[8,9]$. Patients recommended for HSG are under pressure to alleviate the burden and stigma of infertility that they care less about the side effects of their examination. Even, large percent of these patients and some referring physicians are ignorant of risks associated with radiation dose. Ignorance of patients and physicians on the health implications of medical radiation examination has been reported $[10,11]$.

During HSG examinations, X-ray beam is focused on the female genital tract thus irradiation of this organ is inevitable in the process. The uterus and ovaries are known to receive the highest dose as the pelvis is irritated. [5, 12]. Involved organ must have the minimum exposure to radiation. Above all, several radiographs are taken in order to visualize different views. The cumulative dose from these exposures may result in the high dose to the region of interest, thereby leading to cancer induction or birth defect. According to literature, most patients recommended for HSG desire pregnancy $[4,13,14]$. As such, optimization of dose and image quality are essential. Though, hysterosalpingography has been considered as a low-risk examination yet, several factors can cause the patient to receive high dose radiation. Variation in protocol from one healthcare institution to another one has been reported [14]. These variations result from limited understanding of procedures, state of available resources and multiple exposures among others. Such lapses can lead to increasing radiation dose to patients.

Hysterosalpingography is supposedly a fluoroscopic procedure and conducted using fluoroscopy facility. Modern fluoroscopic units have incorporated additional features minimizing radiation exposure [14]. However, some study centers employed conventional radiography machine for this purpose. In centers, where fluoroscopic equipment is available, the machines are old and cannot deliver the desired quality outcome. Technical errors and optimization of procedures will be unavoidable and faulted, respectively, thereby, leading to unnecessary irradiation of patients. The use of conventional X-ray machine and analogue fluoroscopy equipment for hysterosalpingography have been reported to deliver high radiation dose to the region of interest as compared to the digital fluoroscopy unit $[4,14]$. If the exposure takes longer time, the dose will be received more by patients. According to [15], exposure time for normal hysterosalpingography and abnormal procedure is about 54 and 100 seconds on the average, respectively. The fluoroscopy procedure resulted in an entrance surface dose (ESD) of about 11 mGy. However, study by [14] using C-arm reported mean exposure time as 4.2 and 14.3 seconds for normal HSG and abnormal procedure, respectively. They estimated the mean ESD as $2.6 \pm 9.8$ $\mathrm{mGy}$ and $6.9 \pm 10.7 \mathrm{mGy}$ for normal procedure and abnormal procedure, respectively. This implies that the use of conventional radiography machine for HSG is prolonged and delivers higher dose than fluoroscopy equipment. This correlation was observed in the study by Sulieman et al. who noted that hysterosalpingography with fluoroscopic technique reduces patient dose by a factor of 3 [16].

Research by [12] recorded a dose of 4.5 $\mathrm{mGy}$ and $6.2 \mathrm{mGy}$ for ovaries and uterus, respectively, during assessment of hysterosalpingography in Italy. A study by [17] reported radiation dose of $2.7 \mathrm{mGy}$ for female gonad with effective dose of $1.2 \mathrm{mSv}$. A similar study conducted to evaluate patient absorbed dose during HSG in Nigerian hospital recorded a mean value of $5.87 \pm 4.56$ with a range of 0.02 to $13.08 \mathrm{mGy}$ [13]. Research carried out by [4] in order to investigate patient dosimetry in hysterosalpingography estimated the mean 
HSG in southwest Nigeria

entrance surface dose to be 14.6 mGy. Similar investigation in Sudan reported mean entrance surface dose to be 20.9 mGy [5]. Complications arising from the irradiation of female pelvis have been reported in the literature. Some defects were noted, including ovarian failure, uterus impairment, premature labour, miscarriages among others [18, 19]. Though the dose due to HSG is relatively low, the tendency for the incidence of cancer induction cannot be overruled.

The goal of this study is to investigate effective dose to patient during hysterosalpingography procedure in order to enhance the optimization of dose and minimize the associated radiation risks. Also to generate baseline data that can be used to benchmark good practice for future research in the study region.

\section{Material and Methods}

The prospective pilot study, was conducted in 4 selected tertiary healthcare institutions in southwest Nigeria designated as SW1, SW2, SW3 and SW4, respectively. The quality control of the X-ray machines was conducted using MagicMax quality control kits (IBA Dosimetry, Germany). A total of 80 patients were examined for a period of six months with 20 patients from each center. Informed consent was obtained from each patient before the commencement of the examination. Institutional consent was obtained from each hospital used and also the Nigerian Institute of Medical Research (NIMR). Radiation dose measurements were made for patients during HSG procedure using thermoluminiscence dosimeters (TLD-100: LiF: Mg, Ti). The TLD chips were obtained from RadPro International $\mathrm{GmbH}$, Germany. The chips were ovenannealed using Carbolite oven made in England. Irradiation of chips was conducted at the Secondary Standard Dosimetry Laboratory (SSDL) of the National Institute of Radiation Protection and Research (NIRPR), Ibadan. Calibration of TLD chips and reader were conducted and TLD chips were read using Harshaw Reader (Model 3500) at the Department of Physics, Obafemi Awolowo university Ile-Ife. Each of the TLDS was enclosed in labelled black polythene pack. A total of three coded chips were used to measure the entrance surface dose (ESD) during each procedure in order to obtain the mean and enhance precision. The chips were attached to an elastic tape and placed in the center of X-rays field where the beam was intercepted by the irradiated part of the patient. These chips were made to remain fixed on the patient throughout the entire procedure.

Patient's clinical information and exposure parameters were noted and recorded using self-structured form. PCXMC software (version 20 Rotation) was used to evaluate the effective and organ doses. Statistical analysis of data was carried out using SPSS (Version 23) and Microsoft excel.

\section{Results}

Specifications of machine used for investigation are presented in Table 1. Analysis of radiation doses, exposure parameters and patients' parameters in each study center are as shown in Table 2. The result obtained showed that infertility $(58 \%)$ is the major cause for

Table 1: Specification of machine used for hysterosalpingography in the study centers.

\begin{tabular}{ccccc} 
Machine Parameters & \multicolumn{4}{c}{ Names of diagnostic centers } \\
\cline { 2 - 5 } & SW1 & SW2 & SW3 & SW4 \\
\hline Name of Machine & Toshiba & GE & Allengers & GE \\
\hline Type of Machine & Computed & Conventional & Computed & Conventional \\
\hline Year of Manufacture & 2011 & 2007 & 2014 & 2010 \\
\hline Filtration (mmAl) & 0.90 & 1.60 & 0.90 & 0.83
\end{tabular}


Achuka J. A. et al

Table 2: Analysis of variance

\begin{tabular}{|c|c|c|c|c|c|c|}
\hline & & $\mathbf{N}$ & Mean & Std. Deviation & Minimum & Maximum \\
\hline \multirow{5}{*}{ ESD } & SW1 & 20 & 18.58 & 6.31 & 10.33 & 31.07 \\
\hline & SW2 & 20 & 15.18 & 2.27 & 10.94 & 18.61 \\
\hline & SW3 & 20 & 17.44 & 3.43 & 11.45 & 21.99 \\
\hline & SW4 & 20 & 34.24 & 11.98 & 20.04 & 61.22 \\
\hline & Total & 80 & 21.36 & 10.28 & 10.33 & 61.22 \\
\hline \multirow{5}{*}{$k V p$} & SW1 & 20 & 92.10 & 5.71 & 84.00 & 100.00 \\
\hline & SW2 & 20 & 74.70 & 3.40 & 70.00 & 78.00 \\
\hline & SW3 & 20 & 91.65 & 6.82 & 82.00 & 105.00 \\
\hline & SW4 & 20 & 87.25 & 3.80 & 80.00 & 90.00 \\
\hline & Total & 80 & 86.43 & 8.68 & 70.00 & 105.00 \\
\hline \multirow{5}{*}{ mAs } & SW1 & 20 & 26.20 & 2.59 & 24.00 & 30.00 \\
\hline & SW2 & 20 & 26.80 & 4.74 & 20.00 & 32.00 \\
\hline & SW3 & 20 & 34.50 & 15.97 & 25.00 & 75.00 \\
\hline & SW4 & 20 & 82.10 & 20.01 & 64.00 & 125.00 \\
\hline & Total & 80 & 42.40 & 26.60 & 20.00 & 125.00 \\
\hline \multirow{5}{*}{ FDD } & SW1 & 20 & 100.75 & 5.91 & 90.00 & 110.00 \\
\hline & SW2 & 20 & 103.50 & 4.89 & 100.00 & 115.00 \\
\hline & SW3 & 20 & 100.75 & 5.91 & 90.00 & 110.00 \\
\hline & SW4 & 20 & 96.00 & 13.73 & 70.00 & 110.00 \\
\hline & Total & 80 & 100.25 & 8.67 & 70.00 & 115.00 \\
\hline \multirow{5}{*}{ FSD } & SW1 & 20 & 71.75 & 2.88 & 65.00 & 75.00 \\
\hline & SW2 & 20 & 78.05 & 4.08 & 72.00 & 89.00 \\
\hline & SW3 & 20 & 74.15 & 4.37 & 68.00 & 83.00 \\
\hline & SW4 & 20 & 70.25 & 13.04 & 41.00 & 88.00 \\
\hline & Total & 80 & 73.55 & 7.76 & 41.00 & 89.00 \\
\hline \multirow{5}{*}{ BMI } & SW1 & 20 & 26.58 & 3.19 & 21.48 & 34.77 \\
\hline & SW2 & 20 & 23.64 & 2.38 & 19.92 & 28.13 \\
\hline & SW3 & 20 & 25.59 & 2.89 & 19.14 & 30.08 \\
\hline & SW4 & 20 & 26.31 & 2.62 & 21.88 & 31.25 \\
\hline & Total & 80 & 25.53 & 2.97 & 19.14 & 34.77 \\
\hline \multirow{5}{*}{ Age } & SW1 & 20 & 35.90 & 4.81 & 27.00 & 49.00 \\
\hline & SW2 & 20 & 36.00 & 3.32 & 30.00 & 41.00 \\
\hline & SW3 & 20 & 34.35 & 3.13 & 28.00 & 40.00 \\
\hline & SW4 & 20 & 33.70 & 3.28 & 29.00 & 39.00 \\
\hline & Total & 80 & 34.99 & 3.76 & 27.00 & 49.00 \\
\hline
\end{tabular}

$\mathrm{ESD}=$ entrance surface dose, $\mathrm{kVp}=$ Kilovoltage peak, $\mathrm{mAs}=$ current time product, $\mathrm{FDD}=$ focus detector distance, $\mathrm{FSD}=$ focus skin distance, $\mathrm{BMI}=$ Body mass index 
HSG in southwest Nigeria

HSG examinations in the study centers as depicted in Figure 1. Sample of 5 anatomical views of HSG in one of the study centers is as shown in Figure 2. The means entrance surface dose (ESD) obtained from the four centers were $18.58 \pm 6.31 \mathrm{mGy}, \quad 15.18 \pm 2.27$ $\mathrm{mGy}, 17.44 \pm 3.43 \mathrm{mGy}$ and $34.24 \pm 11.98 \mathrm{mGy}$ for SW1, SW2, SW3 and SW4 centers, respectively. The corresponding mean effective doses were $1.54 \pm 0.63 \mathrm{mSv}, 1.24 \pm 0.28 \mathrm{mSv}$, $1.41 \pm 0.30 \mathrm{mSv}$ and $2.53 \pm 0.94 \mathrm{mSv}$ for $\mathrm{SW} 1$, SW2, SW3 and SW4 centers, respectively as shown in Figure 3. The doses of ovary, uterus and urinary bladder are $3.51 \mathrm{mGy}, 4.35 \mathrm{mGy}$ and $8.98 \mathrm{mGy}$ for SW1, respectively, 2.81 mGy, $3.49 \mathrm{mGy}$ and $7.23 \mathrm{mGy}$ for SW2, respectively, $2.96 \mathrm{mGy}, 3.87 \mathrm{mGy}$ and 8.31 $\mathrm{mGy}$ for SW3, respectively, and $5.54 \mathrm{mGy}$, $6.95 \mathrm{mGy}$, and $14.68 \mathrm{mGy}$ for SW4, respectively, as shown in Figures 4. Correlation plots between the measured entrance surface dose (ESD) and exposure parameters are presented in Figure 5. Figure 6 compares the results obtained in this study with similar studies in lit-

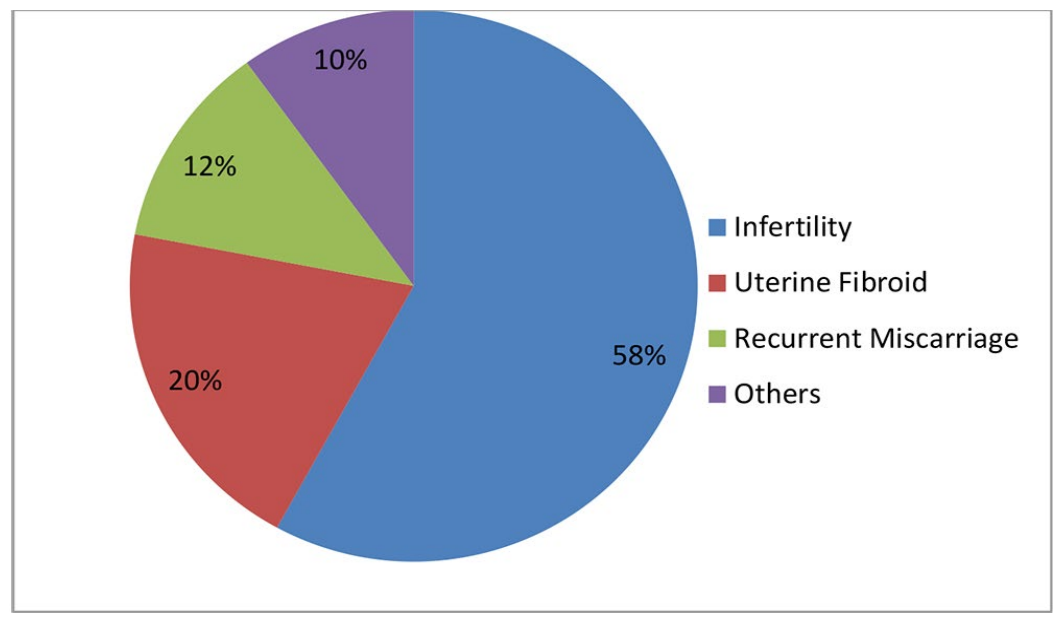

Figure 1: Indications for hysterosalpingography examinations.

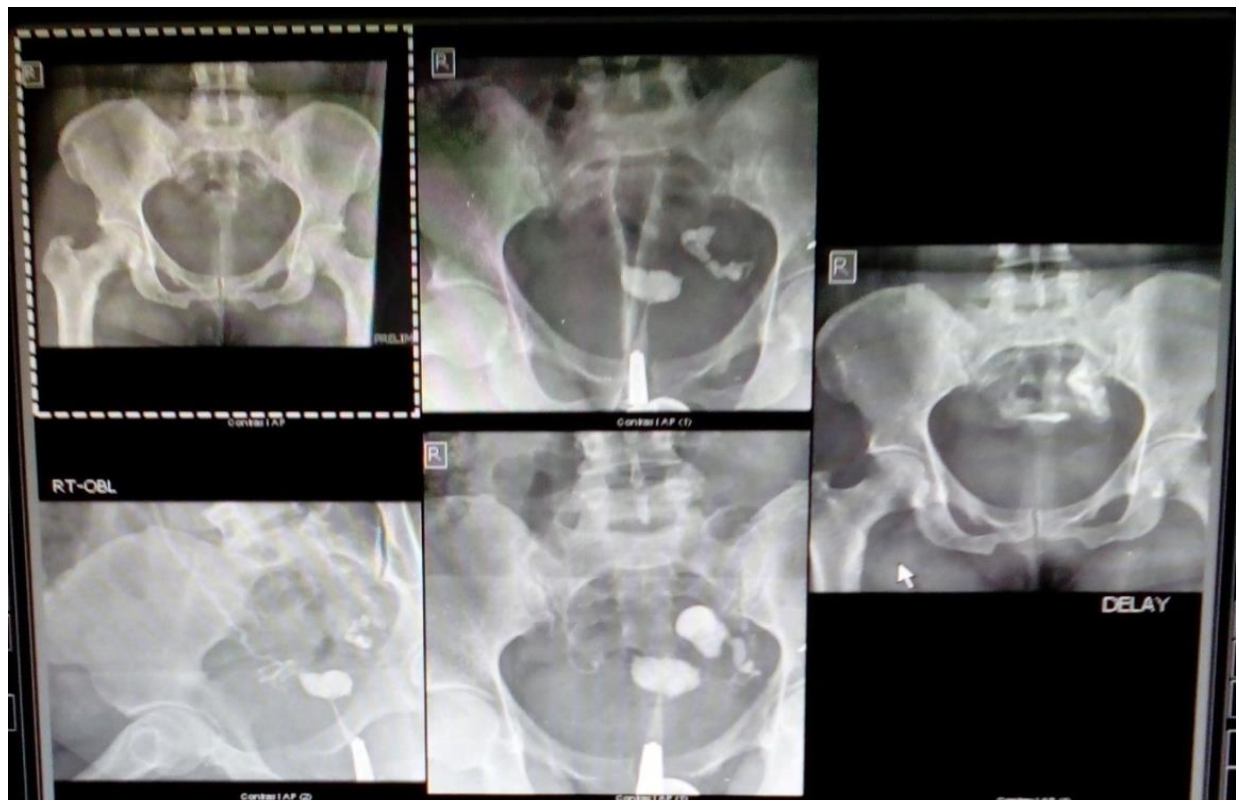

Figure 2: Five anatomical views during hysterosalpingography in one of the study center. 
Achuka J. A. et al

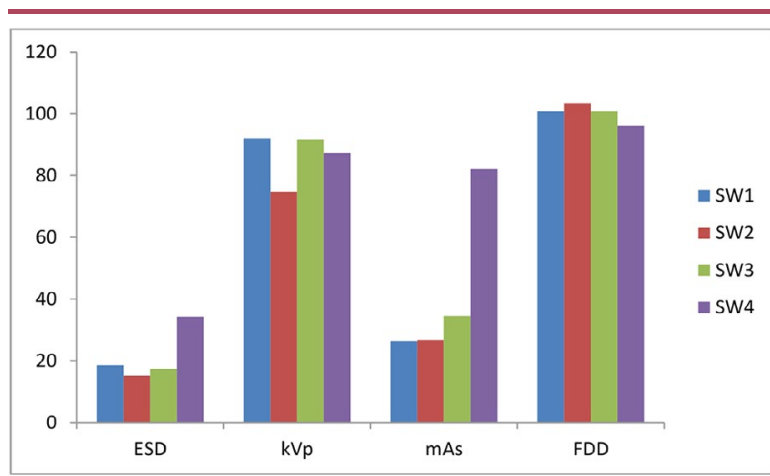

Figure 3: Chart showing the mean entrance surface dose and exposure parameters in the study centers.

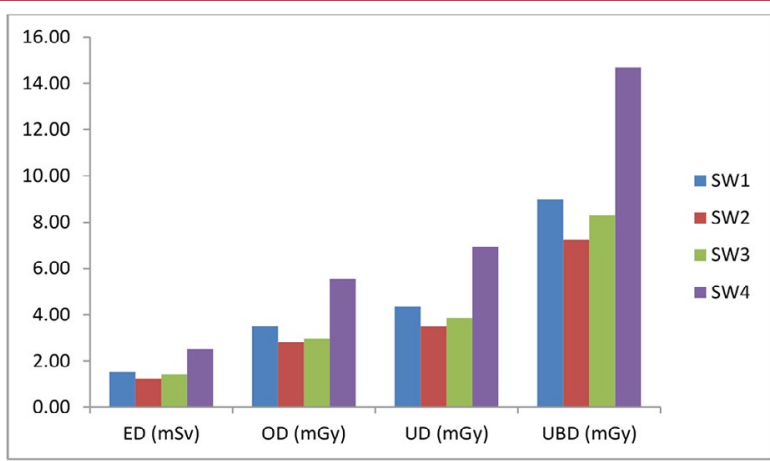

Figure 4: Chart showing the mean effective dose (ED), ovarian dose (OD), uterus dose (UD) and urinary bladder dose (UBD) in the study centres.
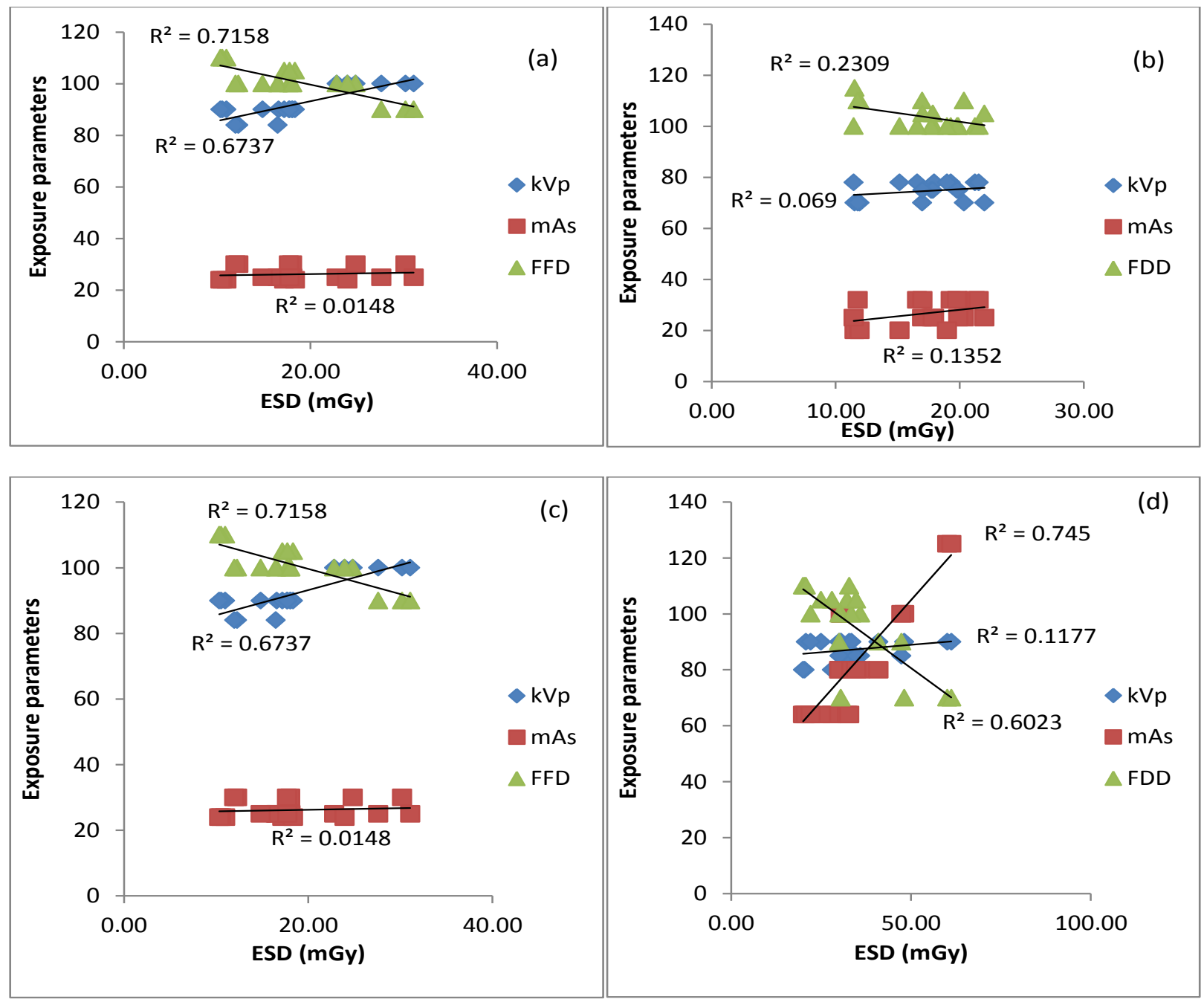

Figure 5: Correlation plots between ESD and exposure parameters (a) centre SW1 (b) centre SW2 (c) centre SW3 (d) centre SW4. 


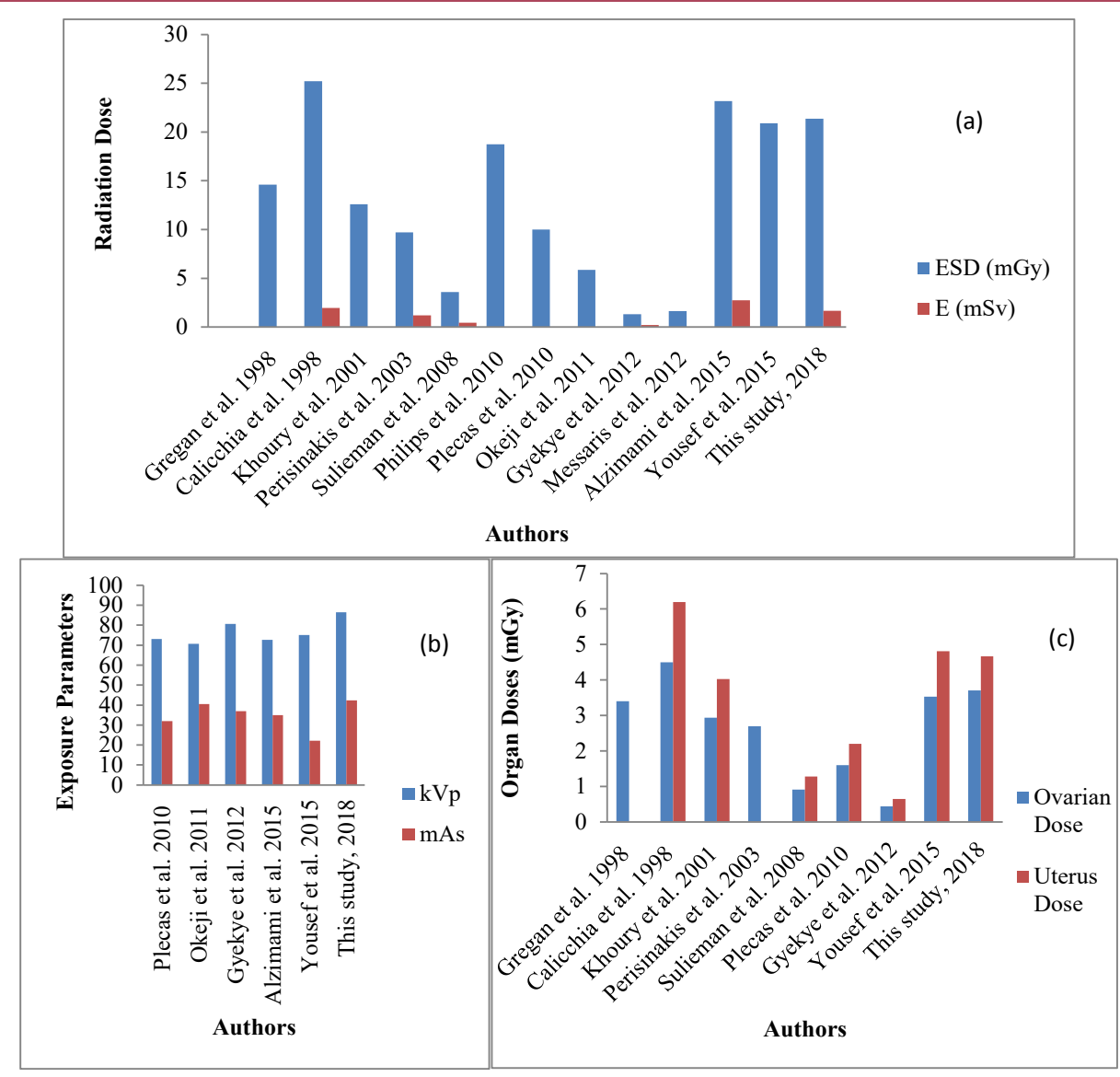

Figure 6: Comparison of (a) entrance surface dose (ESD) and effective dose (E) (b) exposure parameters (c) organ dose with other authors.

erature.

\section{Discussion}

Several studies have been conducted on hysterosalpingography (HSG) in different parts of the world $[2,3,8]$. To the best of our knowledge, no study has been conducted on radiation dose measurement during the procedures in Southwest, Nigeria. The work of Okeji et al. was conducted in Southeast Nigeria and so far the only one reported in literature with regards to radiation dose measurement [13]. The world over, few studies have been published regarding the radiation doses received by patients during HSG. Similar observation has been noted by other authors [4, 20]. HSG examinations are often conducted due to infertility [8, 21]. Same one was observed in this study. The prevalence of infertility in Sub-Sahara Africa is widely reported $[6,7]$. It is essential that radiation dose absorbed by patients during the procedure is monitored in order to minimize the risks to irradiated reproductive organs.

Imaging modalities have been noted to deliver to patients in a wide range of doses [20, 22-27]. Same trend has been observed in this study; there is a large variation in the entrance surface dose (ESD) within the same hospital and from one center to others (Table 2). The disparity between the minimum and maximum ESD in the study centers is in the ratio $1: 3.0,1: 1.7,1: 1.9$ and 1:3.1 for SW1, SW2, SW3 and SW4, respectively. The large variations within the same hospital are traceable to inconsistency in the selection of exposure parameters, inadequate quality control measures, 
and lack of uniform protocol and multi-tasking of imaging system among others. Variation between hospitals can be linked to the usage of different equipment (Table 1) and lack of guidance level for references.

However, the mean entrance surface dose (ESD) in this study is comparable except for center SW4. This implies dose harmonization is possible from one hospital to another one. The high dose recorded in center SW4 was due to the type of imaging system and inadequate quality control measures. The conventional radiography machine used in the center is the capacitive type. The mechanism of the equipment sometimes warranted taking repeated exposure that consequently increased the ESD. Another paramount factor is the high tube current used. There was strong correlation between the ESD and mAs as shown in Figure 5d. ESD is proportional to the tube current and boosts as tube current increase [20, 22].

The lower ESD values reported for SW1 and SW3 center are attributable to the use of computed radiography. Digital systems are known to deliver lower dose as compared to conventional radiography $[4,14]$. In addition, the centers dedicated an X-ray machine specifically for fluoroscopic procedures. Such decision enhances the efficiency of machine and consequently the machine output. Center SW2 has the least range and the lowest mean ESD. Lower ESD values recorded is traceable to the correct use of exposure parameters. The center uses lower $\mathrm{kVp}$ and $\mathrm{mAs}$ values while the FFD was higher as compared to other centers. This is indicative of adherence to ALARA (as low as reasonably achievable) principle and skillful personnel in the center. Furthermore, the participants in this center have had lower body mass index (BMI) in general. Since tube voltage is chosen according to patient BMI, invariably low BMI will culminate in low dose. The influence of exposure parameters on ESD is paramount as a little shift in every parameter has a significant impact on the patient absorbed dose (Figure 5). It is on this basis the radiation regulatory authorities demand optimization of procedure.

Effective dose (ED) is a measure of radiation risk. The mean effective dose in the centers ranged from $1.24 \mathrm{mSv}$ in center SW2 to $2.53 \mathrm{mSv}$ in center SW4. Since effective dose is evaluated by ESD, its value will follow the same trend as ESD values in the study centers. Same trend follows for the evaluated organ doses (ovary, uterus, urinary bladder) as shown in Figure 4. Center SW2 has the least doses given by $2.81 \mathrm{mGy}, 3.49 \mathrm{mGy}$ and 7.23 $\mathrm{mGy}$ for ovary, uterus and urinary bladder doses, respectively. Centre SW4 has the highest values given by $5.54 \mathrm{mGy}, 6.95 \mathrm{mGy}$ and $14.68 \mathrm{mGy}$ in the same order. In all the centers, urinary bladder doses were higher than ovary and uterus doses. Similar results have been noted by other authors [5, 28]. This is due to the position of the bladder with respect to the irradiated organ.

The range of ESD values reported in this study is comparable with many results reported in literature (Figure 6a). Though the cumulative mean ESD value (21.36 mGy) is higher than some previous studies, this can be attributed to the result from center SW4. Moreover, the tube voltage used in this study is somewhat higher than that used by other authors. The study of [20] recorded a higher dose with lower tube voltage to the present study. The type of TLD used by the authors might be responsible for this anomaly. For [12], the tube voltage was not reported, but the ESD value was higher than that from this study. The mean ESD value obtained by [5] is in close approximation with present study. This confirms the possibility of dose harmonization. Although it has been reported that doses from fluoroscopy procedures can vary as much as ten times for the same fluoroscopy time [29]. The method employed in the determination of ESD by various authors, the choice of exposure parameters, the specificity of imaging equipment among others are some of the significant fac- 
HSG in southwest Nigeria

tors responsible for patient dose variability.

Cumulative effective dose from this study is also comparable with previous studies (Figure $6 a)$. The contrast in some values is due to various software and formulae used to estimate effective dose by various authors. United $\mathrm{Na}-$ tions Scientific Committee on the Effects of Atomic Radiation [30] gave a value of $1.2 \mathrm{mSv}$ for effective dose arising from hysterosalpingography. This value is for single author. It is important that doses from several authors are harvested to enable the development of guidance level, thereby minimizing patient dose. Similarly, the organ doses from this study are comparable with other studies (Figure 6c). The disparity noted is attributable to tools of estimation used by other authors. Above all, parameters influencing the ESD value reported in this study are also contributing factors responsible for the variation in effective and organ doses. Previous authors did not report doses to the urinary bladder, except for [5, 28]. This explains why the value was not in Figure 6c. Radiation doses during hysterosalpingography cannot be overlooked irrespective of the dose value because cancer induction has no threshold. More so, reproductive organs aspiring for fertility are being irradiated and these organs are highly sensitive to radiation. It is therefore essential that periodic dose audit be conducted for optimization.

\section{Conclusion}

The measurement of radiation dose during hysterosalpingography was investigated using thermoluminescence dosimeters. The dose indices evaluated were relatively high but comparable to previous studies. Significant factors that influenced doses in the study centers consist of the quality and usage of imaging equipment, exposure parameters, the level of skill expertise and adherence to ALARA principle. Results of our study revealed the possibility of dose harmonization between hospitals with variant equipment and protocol. The authors recommend comprehensive clinical audit in centers with high doses.

\section{Acknowledgment}

We would like to extend our appreciation to the Center for Research, Innovation and Discovery (CUCRID), Covenant University Ota for financial support of this research. Special thanks to all the Radiographers and Radiologists who assisted in this study and the healthcare institutions used.

\section{Conflict of Interest}

None

\section{References}

1. Simpson Jr WL, Beitia LG, Mester J. Hysterosalpingography: a reemerging study. Radiographics. 2006;26:419-31. doi: 10.1148/rg.262055109. PubMed PMID: 16549607.

2. Hernández J, Pineda R, editors. Hysterosalpingography: technique, findings and results from our experience. European Congress of Radiology; Vienna: ECR; 2014.

3. Zafarani F, Ahmadi F, Shahrzad G. Hysterosalpingography in the Assessment of Congenital Cervical Anomalies. Int J Fertil Steril. 2017;11:71-8. doi: 10.22074/ijfs.2017.4716. PubMed PMID: 28670423. PubMed PMCID: PMC5347453.

4. Gregan AC, Peach D, McHugo JM. Patient dosimetry in hysterosalpingography: a comparative study. $\mathrm{Br} J$ Radiol. 1998;71:1058-61. doi: 10.1259/ bjr.71.850.10211066. PubMed PMID: 10211066.

5. Yousef M, Tambul JY, Sulieman A. Radiation dose measurements during hysterosalpingography. Sudan Medical Monitor. 2014;9:15-18. doi:10.4103/1858-5000.144652.

6 . Sembuya R. Mother of nothing: the agony of infertility. Bulletin of the World Health Organization. 2010;88:881-2. doi: 10.2471/BLT.10.011210.

7. Odewale BJ, Oladosun M, Amoo EO. Fertility desire and contraceptive use among women in Nigeria. 3rd International Conference on African Development Issues (CU-ICADI); Ota, Nigeria: Covenant University; 2016.

8. Ikubor JE, Eze GU. Patterns of hysterosalpingographic findings in tertiary hospital, south-south Nigeria: A three year reviews. Afr J Tr Med Biomed Res. 2016;3:34-40.

9. Olatunji A, Jagun 0, Toyobo 0, Ashaolu 0, Adekoya 0 . Hysterosalpingogram findings among women with infertility in Ogun State, Nigeria. Annals of Health Research. 2017;3:75-81.

10. Wong CS, Huang B, Sin HK, Wong WL, Yiu KL, 
Chu Yiu Ching T. A questionnaire study assessing local physicians, radiologists and interns' knowledge and practice pertaining to radiation exposure related to radiological imaging. Eur J Radiol. 2012;81:e264-8. doi: 10.1016/j.ejrad.2011.02.022. PubMed PMID: 21439746.

11. Bosanquet DC, Green G, Bosanquet AJ, Galland RB, Gower-Thomas K, Lewis MH. Doctors' knowledge of radiation - a two-centre study and historical comparison. Clin Radiol. 2011;66:748-51. doi: 10.1016/j.crad.2011.03.009. PubMed PMID: 21546010.

12. Calicchia A, Chiacchiararelli L, De Felice C, Gigliotti T, Indovina PL, Mazzei F, et al. Assessment of radiation dose to patients in hysterosalpingography. Radiol Med. 1998;95:93-7. PubMed PMID: 9636734.

13. Okeji MC, Udoh BE, Chiaghanam NO. Evaluation of Absorbed dose during Hysterosalpingography in a Nigerian Hospital. European Journal of Scientific Research. 2011;67:137-9.

14. Phillips J, Cochavi S, Silberzweig JE. Hysterosalpingography with use of mobile C-arm fluoroscopy. Fertil Steril. 2010;93:2065-8. doi: 10.1016/j. fertnstert.2008.12.135. PubMed PMID: 19200983.

15. Karande VC, Pratt DE, Balin MS, Levrant SG, Morris $\mathrm{RS}$, Gleicher N. What is the radiation exposure to patients during a gynecoradiologic procedure? Fertil Steril. 1997;67:401-3. doi: 10.1016/S00150282(97)81931-0. PubMed PMID: 9022623.

16. Sulieman A, Theodorou K, Vlychou M, Topaltzikis $T$, Roundas C, Fezoulidis I, et al. Radiation dose optimisation and risk estimation to patients and staff during hysterosalpingography. Radiat Prot Dosimetry. 2008;128:217-26. doi: 10.1093/rpd/ ncm324. PubMed PMID: 17584732.

17. Perisinakis K, Damilakis J, Grammatikakis J, Theocharopoulos N, Gourtsoyiannis N. Radiogenic risks from hysterosalpingography. Eur Radiol. 2003;13:1522-8. doi: 10.1007/s00330-002-18090.

18. Critchley HO, Bath LE, Wallace WH. Radiation damage to the uterus - review of the effects of treatment of childhood cancer. Hum Fertil (Camb). 2002;5:616. doi: 10.1080/1464727022000198942. PubMed PMID: 12082209.

19. Kim SY, Kim SK, Lee JR, Woodruff TK. Ovary is necessary to the health of uterus. J Gynecol Oncol. 2016;27:e35. doi: 10.3802/jgo.2016.27. e35. PubMed PMID: 27029755. PubMed PMCID: PMC4823365.

20. Alzimami K, Sulieman A, Babikir E, Alsafi K, Alkhorayef $\mathrm{M}$, Omer $\mathrm{H}$. Estimation of effective dose during hystrosalpingography procedures in certain hospitals in Sudan. Appl Radiat Isot. 2015;100:26. doi: 10.1016/j.apradiso.2015.02.009.
21. Parry RA, Glaze SA, Archer BR. The AAPM/ RSNA physics tutorial for residents. Typical patient radiation doses in diagnostic radiology. Radiographics. 1999;19:1289-302. doi: 10.1148/ radiographics.19.5.g99se211289. PubMed PMID: 10489180.

22. Hough DM, Fletcher JG, Grant KL, Fidler JL, Yu $\mathrm{L}$, Geske JR, et al. Lowering kilovoltage to reduce radiation dose in contrast-enhanced abdominal CT: initial assessment of a prototype automated kilovoltage selection tool. AJR Am J Roentgenol. 2012;199:1070-7. doi: 10.2214/AJR.12.8637. PubMed PMID: 23096181.

23. Achuka JA, Aweda MA, Usikalu MR, Aborisade $C A$. Cancer risks from chest radiography of young adults: A pilot study at a health facility in South West Nigeria. Data in Brief. 2018;19:1250-6. doi: 10.1016/j.dib.2018.05.123. PubMed PMID: 30229004. PubMed PMCID: PMC6140361.

24. Achuka J, Aweda M, Usikalu M. Cancer risks from head radiography procedures. IOP Conference Series: Earth and Environmental Science; IOP Publishing; 2018:173:012038. doi: 1 0.1088/17551315/173/1/012038.

25. Khoury HJ, Maia A, Oliveira M, Kramer R, Drexler $\mathrm{G}$. Patient dosimetry in hysterosalpingography. International conference on radiological protection of patients in diagnostic and interventional radiology, nuclear medicine and radiotherapy; Malaga, Vienna: IAEA; 2001. P. 139-142.

26. Plećaš DV, Živković MM, Ciraj-Bjelac OF. Radiation dose and risk assessment in hysterosalpingography. Nuclear Technology and Radiation Protection. 2010;25:217-21. doi:10.2298/NTRP103217P.

27. Messaris GA, Abatzis I, Kagadis GC, Samartzis AP, Athanasopoulou P, Christeas N, et al. Hysterosalpingography using a flat panel unit: evaluation and optimization of ovarian radiation dose. Med Phys. 2012;39:4404-13. doi: 10.1118/1.4729715. PubMed PMID: 22830773.

28. Gyekye PK, Emi-Reynolds G, Boadu M, Darko EO, Yeboah J, Inkoom S, et al. Cancer incidence risks to patients due to hysterosalpingography. J Med Phys. 2012;37:112-6. doi: 10.4103/09716203.94747. PubMed PMID: 22557802. PubMed PMCID: PMC3339143.

29. International Atomic Energy Agency (IAEA). Applying Radiation Safety Standards in Diagnostic Radiology and Interventional Procedures Using X Ray. Safety Reports Series 39: International Atomic Energy Agency; Vienna: IAEA; 2006. p. 77.

30. United Nations Scientific Committee on the Effects of Atomic Radiation (UNSCEAR). Sources and effects of ionizing radiation: sources. New York: United Nations Publications; 2008. p. 77. 